Thorax 1984;39:121-124

\title{
Wound prophylaxis in thoracic surgery: a new approach
}

\author{
WS WALKER, A FAICHNEY, T RAYCHAUDHURY, RJ PRESCOTT, MA CALDER, CTM \\ SANG, EWJ CAMERON, PR WALBAUM \\ From the Departments of Cardiothoracic Surgery, Edinburgh Royal Infirmary and City Hospital; the Medical \\ Computing and Statistics Unit, University of Edinburgh; and the Department of Bacteriology, City Hospital, \\ Edinburgh
}

ABSTRACT A prospective double blind, randomised study was performed in 100 patients undergoing major elective thoracic surgery to assess a new method of prophylaxis of wound infection using one preincisional intraparietal infiltration of cefuroxime sodium along the line of proposed incision as the sole protection against wound infection. A significant $(p<0.01)$ reduction in the incidence of wound infection occurred in the antibiotic treated group (2\%) compared with the control group ( $20 \%$ ), who received by the same route the same volume of saline only. The groups were comparable with respect to age, sex, pathological condition, and operative variables. The use of additional antibiotics was significantly greater in the control group $(p<0.01)$, largely owing to a much greater incidence of postoperative pulmonary infection in the control group (60\%) than in the antibiotic treated group $(40 \%)$. No morbidity was associated with this technique. The organisms found in oesophageal and bronchial operative luminal specimens did not correlate with postoperative wound or pulmonary infection or with organisms causing these infections. Reductions in wound and pulmonary infection rates equivalent to those produced by conventional multiple dose parenteral regimens were achieved by this technique.

The prophylactic use of parenteral antibiotics, in various multiple dose regimens, has been known for some time to reduce the incidence of postoperative wound infection in general, orthopaedic, and urological surgery. More recently, studies in cardiac ${ }^{2}$ and thoracic ${ }^{3}$ surgery have shown a similar benefit, particularly with cephalosporins. Although infiltration of wounds with antibiotic at operation has been described ${ }^{4}$ and topical application at surgery has long been practised, the infiltration of an antibiotic into the superficial tissues along the line of an intended incision before this is made is an entirely new technique, which has recently been described and shown to be effective as a one dose prophylactic measure in general surgical cases. ${ }^{5}$ Tissue and serum concentrations of antibiotic with this technique are similar to those resulting from conventional parenteral routes of administration. ${ }^{6}$ It is clearly desirable to minimise antibiotic use and yet maintain adequate prophylaxis against infection. A

Address for reprint requests: Mr WS Walker, Department of Cardiothoracic Surgery, Edinburgh Royal Infirmary, Edinburgh.

Accepted 24 October 1983 study was therefore undertaken to evaluate this simple, logical technique in thoracic surgical cases.

\section{Methods}

One hundred patients undergoing major elective thoracic surgical procedures were randomly allocated to receive either cefuroxime sodium $1.5 \mathrm{~g}$ in $40 \mathrm{ml}$ of normal saline (study group) or the same volume of normal saline alone (control group) by infiltration into the subcutaneous tissues and superficial muscle layers along the line of the proposed incision. This was performed with a masked syringe and 18 gauge spinal needle after induction of anaesthesia and before skin preparation and draping, alcohol being used to sterilise the injection sites before skin puncture. The skin was prepared with either $10 \%$ providone iodine in alcohol or chlorohexidine gluconate $0.5 \%$ in alcohol. Subsequent analysis did not determine any bias in wound infection rate towards either substance. Neither the administering surgeon nor the subsequent wound assessor was aware of the option drawn.

All the surgeons who took part in this study have 
generally similar operating technique and wound closure was standardised throughout. Heavy polyglycolic acid was used for rib approximation and closure of the fascial layers and for closure of the peritoneum when this was opened. Skin closure was achieved with a continuous simple silk suture. The same anaesthetic protocols were in practice throughout and the operating room personnel pool was constant. When the oesophagus or a bronchus was opened dry bacteriology swabs were taken for culture to assess potential contamination and correlate the organisms with those found in subsequent infections.

Each patient's age, sex, diagnosis, and operation were recorded, together with the length of time rib retractors were in situ, the operation time, and the operative blood loss. A note was made of any other antibiotics prescribed before or after operation.

The wounds were examined daily by one of us (either WSW or AF), the assessor being unaware of which patients were having which of the trial options, and dry bacteriology swabs were taken from any discharge for culture. The bacteriology swabs from the wounds and those taken at operation were treated in the same way. There was rapid transport to the bacteriology laboratory, where an immediate Gram film was examined and the swabs were plated out onto a blood agar plate for aerobic culture for 18 hours, a blood agar plate for anaerobic culture for $\mathbf{4 8}$ hours, and a McKonkey agar plate for aerobic culture for 18 hours. The swabs were then immersed in Robertson's culture medium and incubated anaerobically for $\mathbf{4 8}$ hours, after which a Gram film from this culture was examined and the medium subcultured on to plates as before. All incubation was done at $37^{\circ} \mathrm{C}$ and a standard disc difffusion technique was used to determine sensitivity to cefuroxime. For overall analysis wounds showing the clinical features of infection along some portion of their length (redness, swelling, and purulent discharge) were considered to be infected irrespective of the results of wound culture.? Positive cultures were in fact obtained from all but two infected wounds. Empyema formation and wound dehiscence were recorded, as was the development of pulmonary infection, both clinically and as confirmed by positive sputum culture.

All the data were recorded prospectively on proforma sheets with the culture results. The statistical analysis presented here used standard tests of significance: $\chi^{2}$ or Fisher's exact test with qualitative data and the $t$ test or Wilcoxon rank sum test with quantitative data. Two tailed tests were used throughout. Linear logistic models ${ }^{8}$ were used to investigate further factors influencing the develop- ment of wound infection, but as the results from this approach were the same as those obtained with the simpler standard tests only the results of the simpler approach are given. For the sake of absolute reliability the analysis was restricted to those infected cases with positive wound cultures.

Before the start of this study ethical permission was obtained from the Ethical Subcommittee of the South Lothian Division of Surgery.

\section{Results}

There was no difference between the two groups with respect to age, sex, preoperative haemoglobin concentration, malignancy, and operative variables; but the use of additional antibiotics was significantly greater $(p<0.01)$ in the control group (table 1$)$. The spread of diagnoses (table 2) and nature of the surgery performed (table 3 ) were similar.

There were 10 wound infections $(20 \%)$ in the control group and only one (2\%) in the study group $(p<0.01$, Fisher's exact test). The patient in the study group who is recorded as having a wound infection had only a slight discharge, which grew only Staphylococcus albus. Most of the other wound

Table 1 Comparison of recorded data on the patients

\begin{tabular}{|c|c|c|c|c|}
\hline \multirow[t]{2}{*}{ Variable } & \multicolumn{2}{|c|}{$\begin{array}{l}\text { Study }(n=50) \\
\text { group }\end{array}$} & \multicolumn{2}{|c|}{$\begin{array}{l}\text { Control }(n=50) \\
\text { group }\end{array}$} \\
\hline & Mean & $S D$ & Mean & $S D$ \\
\hline \multirow{6}{*}{$\begin{array}{l}\text { Age (y) } \\
\text { Preoperative } \\
\text { haemoglobin (g/dl) } \\
\text { Male } \\
\text { Malignant disease } \\
\text { Operation time (min) } \\
\text { Retraction time (min) } \\
\text { Operative blood loss } \\
\text { (mls) } \\
\text { Preoperative } \\
\text { antibiotics given } \\
\text { Postoperative } \\
\text { antibiotics given }\end{array}$} & $56 \cdot 88$ & 13.04 & $58 \cdot 64$ & 10.47 \\
\hline & $\begin{array}{l}13 \cdot 83 \\
32(64 \%) \\
35(70 \%)\end{array}$ & 1.53 & $\begin{array}{l}14 \cdot 10 \\
36(72 \%) \\
34(68 \%)\end{array}$ & 1.64 \\
\hline & $\begin{array}{c}105 \cdot 88 \\
64 \cdot 12\end{array}$ & $\begin{array}{l}45 \cdot 45 \\
40 \cdot 86\end{array}$ & $\begin{array}{l}99.64 \\
62.94\end{array}$ & $\begin{array}{l}42 \cdot 63 \\
36 \cdot 78\end{array}$ \\
\hline & $515 \cdot 40$ & $414 \cdot 01$ & 672.94 & 836.66 \\
\hline & 3 & - & 2 & - \\
\hline & 18 & - & 33 & - $^{*}$ \\
\hline
\end{tabular}

${ }^{*} \chi^{2}=7 \cdot 8, p<0 \cdot 01 ;$ none of the other differences is significant at the $10 \%$ level.

Table 2 Comparison of diagnoses in the trial patients

\begin{tabular}{lll}
\hline & $\begin{array}{l}\text { Study group } \\
(n=50)\end{array}$ & $\begin{array}{l}\text { Control group } \\
(n=50)\end{array}$ \\
\hline $\begin{array}{l}\text { Pulmonary } \\
\text { Malignant } \\
\text { Benign }\end{array}$ & 23 & 27 \\
$\begin{array}{l}\text { Oesophagogastric } \\
\text { Malignant }\end{array}$ & 6 & 4 \\
$\quad$ Benign & 10 & 7 \\
$\begin{array}{l}\text { Other } \\
\text { Mitral stenosis } \\
\text { Miscellaneous }\end{array}$ & 6 & 9 \\
\hline
\end{tabular}


Table 3 Comparison of surgery performed in the trial patients

\begin{tabular}{lrr}
\hline & $\begin{array}{c}\text { Study group } \\
(n=50)\end{array}$ & $\begin{array}{l}\text { Control group } \\
(n=50)\end{array}$ \\
\hline Incision & 40 & 38 \\
Thoracotomy & 9 & 11 \\
Thoracolaparatomy & 0 & 1 \\
Median sternotomy & 1 & 0 \\
Laparotomy & & \\
Operation & 19 & 20 \\
Pulmonary resection & 5 & 8 \\
Pulmonary, other & 4 & 3 \\
Exploratory thoractomy & 0 \\
Mitral valvotomy (closed) & 4 & 3 \\
Fundoplication & 4 & 4 \\
Intrathoracic, other & 3 & 10 \\
Oesophageal resection & 10 & 2 \\
Open Celestin intubation & 1 & \\
Endogenous contamination risk & 11 \\
Oesophagogastric segment & 10 & 23 \\
opened & 23 & 16 \\
Respiratory tract opened & 23 & \\
None & 17 & \\
\hline
\end{tabular}

infections were due to Staphylococcus aureus (table 4). Three empyemas occurred in the control group and two in the study group. None of the patients in the study group developed a wound dehiscence but some degree of wound disruption occurred in five control group patients (four superficial short segment and one complete) $(10 \%)$; this difference was not, however, significant $(p=0.06)$ at the $5 \%$ level.

Bacteriologically confirmed pulmonary infection developed after operation in eight $(16 \%)$ of the study group cases, compared with $17(34 \%)$ in the control group $\left(\chi^{2}=3.4,0.05<p<0 \cdot 1\right)$. If we include those with clinical pulmonary infection as indicated by pyrexia and purulent sputum, the figures become $20(40 \%)$ and $30(60 \%)$ respectively $\left(x^{2}=3 \cdot 2\right.$, $0 \cdot 05<\mathrm{p}<0 \cdot 1)$. The trend is similar to that observed previously in studies on thoracic surgical wound infection prophylaxis. ${ }^{3}$
Table 5 Comparisons of infected and non-infected control cases*

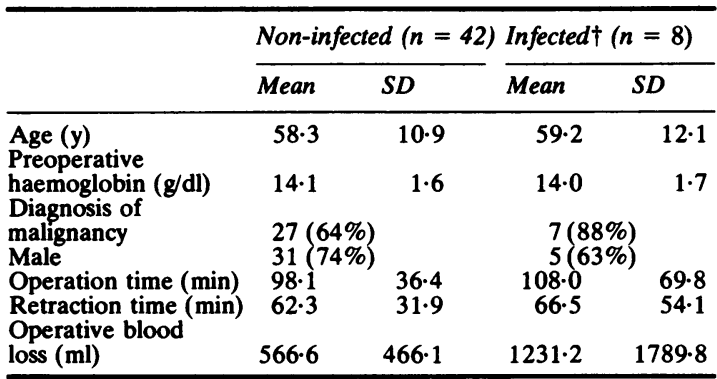

*None of the differences is significant at the $10 \%$ level. †With positive cultures.

No correlation was evident between the oesophageal and bronchial swab cultures and organisms grown from postoperative wound or sputum cultures. By far the commonest postoperative sputum pathogen was Haemophilus infuenzae, which was present in about two thirds of those with pulmonary infection.

Comparison of infected and non-infected cases within the control group (table 5) showed no significant differences, thus failing to identify any clear risk factor for wound infection. The higher mean blood loss in the infected patients was largely due to the loss of 5.5 litres of blood in one patient.

\section{Discussion}

An antibiotic chosen for wound infection prophylaxis must have two features. Firstly, its spectrum should be appropriate to those pathogens likely to be encountered. Secondly, adequate levels of antibiotic should be present both within the wound and in the circulation to combat local implantation and systemic spread of organisms. Cefurox-

Table 4 Cases of infection

\begin{tabular}{|c|c|c|c|c|c|c|}
\hline Age & Group & Sex & Diagnosis & Operation & Peroperative culture & Infecting organisms \\
\hline $\begin{array}{l}64 \\
58 \\
54 \\
69 \\
65 \\
59 \\
72\end{array}$ & $\begin{array}{l}\text { Control } \\
\text { Control } \\
\text { Control } \\
\text { Control } \\
\text { Control } \\
\text { Control } \\
\text { Control }\end{array}$ & $\begin{array}{l}\mathbf{F} \\
\mathbf{F} \\
\mathbf{F} \\
\mathbf{M} \\
\mathbf{M} \\
\mathbf{M} \\
\mathbf{M}\end{array}$ & $\begin{array}{l}\text { Carcinoma bronchus } \\
\text { Haemothorax } \\
\text { Carcinoma oesophagus } \\
\text { Carcinoma bronchus } \\
\text { Carcinoma bronchus } \\
\text { Alveolar cell carcinoma lung } \\
\text { Carcinoma oesophagus }\end{array}$ & $\begin{array}{l}\text { Lobectomy } \\
\text { Decortication } \\
\text { Oesophagogastrectomy } \\
\text { Lobectomy } \\
\text { Exploratory thoracotomy } \\
\text { Pneumonectomy } \\
\text { Oesophagogastrectomy }\end{array}$ & $\begin{array}{l}\text { No growth } \\
\text { No growth } \\
\text { No growth } \\
\text { Streptococcus viridans } \\
\overline{\text { No growth }} \\
\text { Veillonella }\end{array}$ & $\begin{array}{l}\text { Staphylococcus aureus } \\
\text { Coliforms } \\
\text { Staphylococcus aureus } \\
\text { Staphylococcus aureus } \\
\text { Staphylococcus aureus } \\
\text { Staphylococcus aureus } \\
\text { Mixed: Haemophilus infuenzae, } \\
\text { peptococci, Bacteroides sp, } \\
\text { B haemolytic streptocci, } \\
\text { Staphylococcus aureus }\end{array}$ \\
\hline 33 & Control & $\mathbf{M}$ & Carcinoma bronchus & $\begin{array}{l}\text { Pulmonary wedge } \\
\text { resection }\end{array}$ & - & Staphylococcus aureus \\
\hline 62 & Control & $\mathbf{M}$ & $\begin{array}{l}\text { Benign oesophageal } \\
\text { stricture }\end{array}$ & $\begin{array}{l}\text { Subtotal oesophag- } \\
\text { ectomy }\end{array}$ & Candida & Not known \\
\hline $\begin{array}{l}39 \\
57\end{array}$ & $\begin{array}{l}\text { Control } \\
\text { Study }\end{array}$ & $\begin{array}{l}\mathbf{M} \\
\mathbf{M}\end{array}$ & $\begin{array}{l}\text { Carcinoma oesophagus } \\
\text { Carcinoma bronchus }\end{array}$ & $\begin{array}{l}\text { Oesophagogastrectomy } \\
\text { Lobectomy }\end{array}$ & No growth & $\begin{array}{l}\text { Not known } \\
\text { Staphylococcus albus }\end{array}$ \\
\hline
\end{tabular}


ime offers a wide spectrum of activity against both Gram positive and Gram negative organisms ${ }^{9}$ and in particular is an effective antistaphylococcal agent, being strongly resistant to staphylococcal $\beta$ lactamase. ${ }^{10}$ " It also has good resistance to Gram negative $\beta$ lactamases. ${ }^{9}$ Although conventional parenteral administration of antibiotic has been shown to be effective in decreasing wound infection, preincisional infiltration will inevitably produce a higher local wound antibiotic concentration at the time of contamination, while also producing systemic antibiotic levels comparable to conventional parenteral administration ${ }^{6}$ with consequently equal general prophylactic effect.

The source of the staphylococcal wound contamination is obscure. Infection was not particularly associated with any surgeon. Nor was it related to opening potentially contaminated areas since about half of the operative swabs produced no growth and Staphylococcus aureus did not feature at all in our positive bronchial cultures, which yielded growths of haemolytic streptococci, pneumococci, Haemophilus influenzae, coliforms (Escherichia coli in particular), peptococci, Bacteroides, Corynebacterium bovis, and Staphylococcus sanguis. Moreover, $S$ aureus was found in only one of the positive oesophageal cultures, the remainder of which were remarkably innocuous, yielding predominantly Veillonella species but also group F streptococci and Candida.

Interestingly, the infection rate for oesophageal resection surgery in the control group is of the order of $40 \%$, compared with $14 \%$ for pulmonary surgery in the controls. This may relate in part to the fact that oesophageal resection procedures were substantially longer (mean $157 \mathrm{~min}$ ) than the other thoracotomy procedures (mean $87 \mathrm{~min})(\mathrm{p}<0.001$, $t$ test), with a consequently greater exposure to contamination.

The largely benign nature of the oesophageal flora in our cases is of interest and somewhat surprising given the high counts of strepotococci, coliforms, and faecal anaerobes reported as the allegedly normal oesophageal flora. ${ }^{12}$ Possibly swabs taken from the opened viscus, as in our study, avoid the possibility of contamination by saliva, which may contain the full range of faecal organisms, ${ }^{13}$ in aspiration studies.

Haemophilus infuenzae, the major postoperative pulmonary pathogen in this series, is highly susceptible to cefuroxime and the reduction in the incidence of postoperative pulmonary infection in the study group may well represent a systemic prophylactic effect of the locally administered antibiotic, which would be consistent with the high systemic level achieved by the route of administration.
Wound infections are distressing, increase hospital stay, and can have fatal sequelae. Preincisional wound area infiltration with cefuroxime appears to provide a simple and effective method of providing antibiotic prophylaxis against wound infection in thoracic surgery. Furthermore, even though this technique uses only one dose, in contrast to the other multiple doses administered over several days in other studies, the pulmonary benefits of prophylactic antibiotics seem to have been well preserved. In principle, the technique should be applicable to any other suitable antibiotic.

We are grateful to Glaxo UK Ltd, which supplied the cefuroxime sodium used in the trial, and to our operating room staff for their cooperation and help in running this study.

\section{References}

${ }^{1}$ Goldman DA, Hopkins CC, Karchmer AW, et al. Cephalothin prophylaxis in cardiac valve surgery: a prospective, double-blind comparison of two-day and six-day regimens. $J$ Thorac Cardiovasc Surg 1977;73:470-9.

${ }^{2}$ Bain WH, McGeachie J, Lindsay G, Underwood J. The use of cephalothin sodium (Keflin) as the prophylactic antibiotic for open heart surgery. J Antimicrob Chemother 1977;3:339-45.

${ }^{3}$ Ilves R, Cooper JD, Todd TRJ, Griffith-Pearson F. Prospective, randomised double-blind study using prophylactic cephalothin for major, elective general thoracic operations. J Thoracic Cardiovasc Surg 1981;81:813-7.

${ }^{4}$ Hares MM, Hegarty MA, Warlow J, et al. A controlled trial to compare systemic and intra-incisional cerfuroxime prophylaxis in high risk gastric surgery. $\mathrm{Br} J$ Surg 1981;68:276-80.

${ }^{5}$ Taylor TV, Walker WS, Mason RC, Richmond J, Lee D. Preoperative intraparietal (intra-incisional) cefoxitin in abdominal surgery. Br J Surg 1982;69:461-2.

${ }^{6}$ Armstrong CP, Taylor TV, Reeves DS. Pre-incisional intraparietal injection of cephamanadole: a new approach to wound infection prophylaxis. $\mathrm{Br} J$ Surg 1982;69:459-60.

7 Simmons BP. CDC Guideline for prevention of surgical wound infections. Infection Control 1982;3:187-96.

${ }^{8}$ Cox DR. Analysis of binary data. London: Methuen, 14-29.

${ }^{9}$ Goto S. The in vitro and in vivo antibacterial activity of cefuroxime. Proc R Soc Med 1977;9 suppl:56-70.

${ }^{10}$ Garrod LP, Lambert HP, O' Grady F. Antibiotics and chemotherapy 5th ed. Edinburgh: Churchill Livingstone, 1981:108.

" Laverdiere M, Wheeler N, Sabath LD. Cefuroxime resistance to staphylococcal $\beta$ lactamase. Proc $R$ Soc Med 1977;9 suppl:72-3.

${ }^{12}$ Mannell A, Plant M, Frolich J. The microflora of the oesophagus. Ann R Coll Surg Engl 1983;65:152-4.

${ }^{13}$ Drasar BS, Shiner M, McLeod GM. The bacterial flora of the gastro-intestinal tract in healthy and achlorhydric persons. Gastroenterology 1969;56:719. 